\title{
EPIDEMIC OF INFLUENZA B ASSOCIATED WITH LYMPHADENOPATHY
}

\author{
Major A. J. SPICER, \\ M.B., B.S., M.R.C.S., L.R.C.P., R.A.M.C. \\ Military Hospital, Shorncliffe.*
}

A SEARCH of the literature has yielded only one previous record of association of Irifluenza B with a generalised lymphadenopathy (Mackay-Dick, 1962). During March 1965 an epidemic of Influenza B occurred among a Junior Leaders Regiment in Dover in which a generalised lymphadenopathy was a significant feature. Sixty two unselected cases were admitted to hospital for observation and investigation. Twenty of these were regular soldiers from nearby units where smaller outbreaks occurred.

\section{Epidemiology}

The Junior Leaders Regiment is composed of 550 boys between the ages of fifteen and a half and seventeen and a half accommodated in dormitories of six to twelve beds. There are 166 permanent staff most of whom live in quarters. Few of these complained of symptoms and none were hospitalised. The attack rate among the boys was 41 per cent with a rapid rise and fall in incidence as shown in Fig. 1. In only three cases was the duration of contact with the illness before onset of symptoms precisely known. In these the incubation period was two, three and four days.

\section{Symptoms and Signs}

The onset was abrupt. The invariable symptoms were retro-orbital headache, sore throat and unproductive cough accompanied by substernal pain. The cough became productive of sputum in half the cases a few days after onset. Two thirds complained of generalised muscular aches, malaise, chilliness and a feeling of faintness. 16 per cent had an attack of shivering, and 16 per cent suffered nausea and vomiting for a day at the onset. There were no symptoms of nasal congestion or rhinorrhoea, and laryngitis was uncommon.

In all cases there was a generalised shotty lymph gland enlargement which was not apparent on inspection but was obvious to the lightest palpation. The glands were uniformly enlarged in cervical, axillary and inguinal regions. The tonsillar lymph glands were enlarged to the same degree and were not tender. Splenomegaly did not occur. The lymphadenopathy persisted for two to three weeks.

The soft palate, fauces and posterior pharyngeal wall were injected and there was marked enlargement of lymphoid follicles in many cases. There was no formation of exudate. In some cases there was a striking contrast between the complaint of a very sore throat and the appearance of moderate inflammation. In 92 per cent the duration of fever was between one and seven days, with a mean of five days; the temperature ranged between $99^{\circ} \mathrm{F}$ and $102^{\circ} \mathrm{F}$ in the absence of complications. In the other 8 per cent the fever 
FIG. 1. DISEASE INCIDENCE JUNIOR LFADUERS REGDIENT

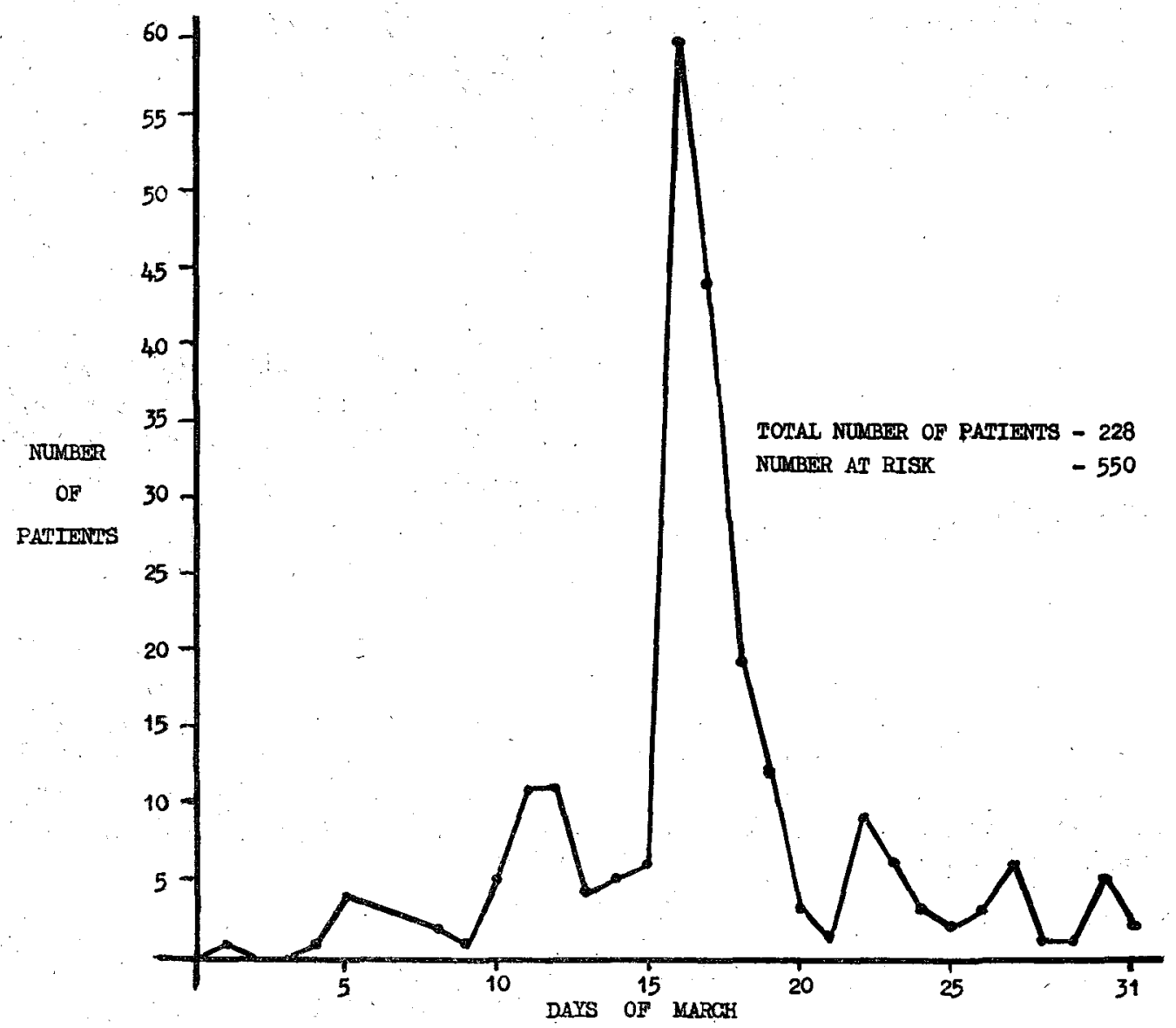

lasted between eight and nineteen days and the highest temperature recorded in an uncomplicated case was $104^{\circ} \mathrm{F}$. 4-6 days after the temperature returned to normal, 19 per cent of patients had a recurrence of fever lasting up to two days. The increase in pulse rate was directly proportional to the rise in temperature, and there was no increase in the respiratory rate.

Convalescence was rapid.

\section{Complications}

Pneumonia or pneumonitis occurred in 12 patients (19 per cent) with an onset two to five days after the beginning of illness. Three patients had classical basal lobar pneumonia. Eight were clinically obvious pneumonitis and one was discovered on X-ray. Pneumonitis was manifested by a rise in temperature and worsening cough with basal crepitations and minimal or absent signs of consolidation. The X-ray appearances were of basal shadowing. Pathogenic bacteria were isolated from seven of these cases. All resolved rapidly on antibiotics. All patients in the series were X-rayed towards the end of the first week of illness. Two cases of malaria, vivax and quartan, were activated into clinical attacks by the virus infection. The quartan was a primary attack. There was one case of pyelitis and one of otitis media. 


\section{Investigations}

White Cell Count was performed on admission and approximately two weeks later. In the absence of secondary infection the total count was within normal limits. The differential leucocyte pattern was abnormal in 55 per cent with an absolute increase in the mononuclear elements and the prescence of atypical cells. The mean differential count was: polymorphs 50 per cent, lymphocytes 33 per cent, monocytes 13 per cent, atypical mononuclears 3 per cent. The latter were characterised by an altered cytoplasm colour and lobulation of nuclei. The highest atypical cell count was 9 per cent and occurred in a total count of 12,000 . Three quarters of the abnormal counts had returned to normal in two weeks.

The Paul Bunnell reaction was negative for the ten patients tested.

Throat Swabs were taken on admission, 19 cases (30 per cent) were harbouring potential pathogens. Seven were thought to be responsible for secondary lung infection.

Virus Investigations

a. Paired sera of one to two weeks interval were taken from 52 patients. 61 per cent had a significant rise of fourfold or greater in antibodies to Influenza B virus. There was no difference clinically or in the leucocyte pattern between patients with and without detectable antibodies.

$b$. Throat swabs were taken in the first three days of illness from 48 patients. Influenza virus B/Eng/84/65 was isolated from one case.

c. Stool specimens were cultured from 26 cases. Polio virus type II was isolated from two patients who had received oral vaccine thirteen days before.

Water ice was used for the transport of specimens for virus study. Had dry ice been available the number of positive cultures might have been increased.

\section{Summary}

An epidemic of Influenza B with an attack rate of 41 per cent in a closed community is described. Sixty two unselected patients were investigated. All had a significant generalised lymphadenopathy. 55 per cent had an abnormal leucocyte pattern. 19 per cent developed pneumonia or pneumonitis. 6 per cent developed other inter-current infection.

\section{REFERENCE}

Mackay-Dick, J. (1962). J. roy. Army. med. Cps. 108, 202.

\section{"Room at the Top"}

Writers with ideas on this subject should see D.C.I. 202 of 1966, which refers to the set subject and conditions of entry for the George Knight Clowes Memorial Prize Essay 1967. 